\title{
Sleep Disturbances in Patients with Parkinson's Disease
}

\author{
Keisuke Suzuki, Tomoyuki Miyamoto, \\ Masayuki Miyamoto, Ayaka Numao, Hideki Sakuta, \\ Hiroaki Fujita, Yuji Watanabe, \\ Masaoki Iwanami and Koichi Hirata
}

Additional information is available at the end of the chapter

\section{Introduction}

Parkinson's disease (PD) is clinically characterized by motor symptoms such as rigidity, bradykinesia, resting tremor, and postural instability, which are caused by the degeneration of striatonigral dopaminergic neurons [1]. Reflecting recent advances in therapeutic options and management in motor disabilities in PD, non-motor symptoms have received considerable attention due to substantial evidence that shows their significant impact on quality of life. Although some non-motor symptoms can be effectively treated by dopaminergic agents, their management and treatment remain clinically challenging [2]. Nonmotor symptoms include sleep disturbances, cognitive impairment, mood disorders, hyposmia, pain, and dysautonomia, among which sleep disturbances are the central issue when considering their impact on disease course and clinical correlation. The presence of sleep disorders in PD was first described by James Parkinson in his "An Essay on the Shaking Palsy" published in 1817 [3].

\footnotetext{
- "In this stage, the sleep becomes much disturbed. The tremulous motion of the limbs occur during sleep, and augment until they awaken the patient, and frequently with much agitation and alarm" -
}

Sleep disturbances in PD are common and multifactorial problems with a reported incidence ranging from approximately $40 \%$ to $90 \%$ [4-7]. Disease-related intrinsic causes include impairment in thalamocortical arousal and degeneration of the brainstem regulatory centers for sleep/wakefulness maintenance and REM sleep [8]. Other causes include nocturnal motor 
symptoms, psychiatric symptoms, dementia, medication use, circadian rhythm sleep disorders, and comorbidities involving sleep apnea syndrome (SAS), restless legs syndrome (RLS), and rapid eye movement sleep behavior disorder (RBD). Table 1 shows the various causes of sleep problems in PD; when patients complain of or are likely to suffer from sleep problems such as difficulty initiating or maintaining sleep, early awakening, or daytime sleepiness, all of the possibilities should be considered in clinical practice, but they are often underestimated. In this chapter, we review the current understanding of sleep problems in PD and the methods used to evaluate these problems, focusing on the PD sleep scale (PDSS) and PDSS-2.

\section{Evaluation of sleep disturbance}

\subsection{Polysomnography}

Polysomnography is the gold standard in the assessment of sleep disorders because it provides sleep status information, including sleep efficiency, sleep latency, and sleep architecture. However, the cost, special equipment required, and limited availability may hamper its routine application. Sleep structure may be altered, reflecting disease-related changes in the brainstem in patients with PD: the degeneration of cholinergic neurons in the basal forebrain and brainstem, including the pedunculopontine nucleus and noradrenergic neurons in the locus coeruleus, results in disorders of REM sleep. A loss of serotoninergic neurons in the raphe nucleus is associated with a decreased percentage of slow-wave sleep [9] (Table 2). However, reported PSG findings on sleep architecture vary [10]. Reduced total sleep time and sleep efficiency were observed in PD patients compared with controls [11-13], although other studies did not find a difference. Reduced total sleep time was associated with increased age and increased levodopa dose [13], whereas the other study showed a weak positive correlation between the mean sleep latency and the daily dose of levodopa [14]. Sleep stages 1 and 2 appear to be unchanged in PD patients $[15,16]$. Slow-wave sleep was reported to be unchanged, decreased, or increased [11, 17, 18]. REM sleep was also shorter or unchanged [11, 13, 19, 20].

These discrepancies may reflect individual night-to-night variation, medication effects, and differences in patient selection in the studies. PSG may detect abnormal REM sleep in PD, namely, REM sleep without atonia, excessive sustained or intermittent elevation of submental tone, or excessive phasic submental or limb twitching, which are required for a diagnosis of RBD. A recent review of case-control PSG studies provides a higher prevalence of RBD in PD than in controls $(0-47 \%$ vs. $0-1.8 \%)$, but no significant increase of obstructive sleep apnea (27-60\% vs. $13-65 \%)$ or periodic limb movements of sleep compared with controls [10]. In contrast, slightly but significantly increased periodic limb movements during sleep were described in patients with PD [21]. The clinical significance of sleep apnea in PD will be discussed later.

Regarding the effect of dopaminergic medication on the sleep architecture in PD, relative to controls, Wailke et al [18] reported that a significantly decreased total sleep time, REM sleep, 


\begin{tabular}{l}
\hline 1. PD-related pathological changes \\
\hline Impairment of the sleep-wake cycle, circadian rhythm sleep disorder, sundown syndrome \\
\hline Impairment of sleep architecture (REM and non-REM sleep) \\
\hline Impairment of the arousal system (orexin, serotonin, noradrenaline, acetylcholine) \\
\hline 2. Nocturnal motor symptoms \\
\hline Wearing-off phenomenon, rigidity, akinesia, tremor, medication-related dyskinesia, dystonia \\
\hline 3. Nocturnal non-motor symptoms \\
\hline Neuropsychiatric symptoms (depression, psychosis, cognitive impairment) \\
Sensory symptoms (pain, dysesthesia, restlessness of the arms or legs) \\
Hallucinations, nightmares and vivid dreams, nocturia \\
\hline 4. Medication use \\
\hline Dopaminergic drugs, anti-psychotics \\
\hline 5. Comorbid primary sleep disorders \\
\hline Sleep apnea syndrome \\
\hline REM sleep behavior disorder \\
\hline Restless legs syndrome, periodic limb movement disorder \\
\hline
\end{tabular}

Table 1. The cause of sleep-related problems in PD

\begin{tabular}{cccc}
\hline Nucleus/area & Main transmitter & Function & Consequence of dysfunction \\
\hline $\begin{array}{c}\text { Pedunculopontine } \\
\text { nucleus }\end{array}$ & Acetylcholine & Regulation of REM sleep & Disorders of REM sleep \\
Locus coeruleus & Noradrenaline & Regulation of REM sleep & Reduction/absence of REM sleep \\
$\begin{array}{c}\text { Area peri-locus } \\
\text { coeruleus }\end{array}$ & GABA, glutamate? & Inhibition of spinal & Loss of muscle atonia during REM \\
Raphe nuclei & Serotonin & Regulation of slow-wave sleep & Reduction of slow-wave sleep \\
\hline
\end{tabular}

Table 2. Impaired sleep architecture in PD [9].

and slow-wave sleep and an increased amount of time spent awake were found in PD patients whose usual dopaminergic treatments were discontinued after noon and that the administration of levodopa had no impact on any of these PSG parameters. In a study evaluating sleep status in de novo patients with PD, the sleep continuity, sleep architecture, and periodic limb movements index were similar between patients and controls, but an increased alpha activity in REM sleep was observed in de novo PD patients [16]. In another case control study including 15 de novo PD patients and 15 controls, compared with controls, the total sleep time and sleep efficiency in the de novo PD group decreased, the stage 1 sleep and the time spent awake increased, and REM sleep was reduced. A higher percentage of REM sleep without atonia in 
patients compared with controls was observed, whereas only one patient clinically manifested RBD [22]. Because RBD precedes the onset of PD and can manifest during the early phase of PD, abnormalities in REM sleep in the early phase of PD are supported by PSG findings.

\subsection{Multiple sleep latency test}

The multiple sleep latency test (MSLT) records the initial sleep latency of four or five sequential naps to evaluate objective daytime sleepiness. In 54 levodopa-treated PD patients who were referred for sleepiness, pathological sleepiness (mean SL $<5 \mathrm{~min}$ ) was observed in $50 \%$ of the 54 patients [14], and a narcolepsy-like phenotype ( $2 \geq$ sleep-onset REM periods) was found in $39 \%$ of the patients. Additionally, Rye et al [23] found that although the mean SL was similar between patients with PD and controls, abnormal sleepiness (mean $\mathrm{SL} \leq 5 \mathrm{~min}$ ) was common (40 of 134 nap opportunities), and sleep-onset REM periods were also observed (13 of 134 nap opportunities) in PD patients. In contrast, Yong et al [13] reported that mean SL did not differ between PD and controls. No differences in mean SL between the levodopa-alone group and the levodopa and dopamine agonist group were reported [20]. In untreated PD patients, the mean SL on MSLT was not different compared with controls (11.7 \pm 4 vs. $12.5 \pm 2 \mathrm{~min}$ ) [22]. The mean SL was in the pathological range $(<8 \mathrm{~min})$ in three PD patients and in none of the controls, and one patient with PD had a single sleep onset REM on MSLT. This observation suggests that some but not all patients exhibit pathological daytime sleepiness as measured by MSLT, irrespective of the quality and amount of nighttime sleep. However, one should note that sleepiness measured by MSLT does not always reflect subjective sleepiness.

\subsection{Questionnaire-based assessment}

\subsubsection{Parkinson's disease sleep scale}

To comprehensively and clinically address PD's common, disease-specific sleep problems, Chaudhuri et al [24] have developed the Parkinson's disease sleep scale (PDSS), a visual analogue scale, including 15 PD-related nocturnal symptoms for assessing nocturnal disability in PD. The subitems of the PDSS address the follows: item 1, overall quality of the night's sleep; items 2/3, sleep onset and maintenance insomnia; items 4/5, nocturnal restlessness; items 6/7, nocturnal psychosis; items 8/9, nocturia; items $10-13$, nocturnal motor symptoms; item 14 , sleep refreshment; and item 15, daytime dozing. This scale measures the patient's subjective evaluation of sleep and does not address the frequency of sleep problems. Scores for a given individual item range from 0 to 10; 10 represents the best and 0 represents the worst score. The maximum total score for PDSS is 150 (patient is free of symptoms associated with sleep disorders).

In the original study [24], PD patients showed a significantly impaired (lower) total PDSS score compared with controls (101.1 \pm 21.7 vs. 120.7 \pm 21.0$)$, and advanced PD patients (Hoehn and Yahr (HY) stage 4-5) had a lower total PDSS score than early/moderate PD patients (HY stage 1-3) and controls. This scale is now regarded as a recommended and reliable scale for screening and assessing sleep disturbance in PD [25]. The PDSS has been validated and used extensively in a number of countries, with a high reliability [26-30]. Our multicenter study also showed 
an impaired total PDSS score in patients with PD compared with controls $(112.8 \pm 25.4$ vs. $126.6 \pm 17.8)$ and revealed more severe nocturnal disturbances measured by PDSS in advancedstage PD patients (HY stage 4) compared with those with early/moderate stages (HY stage 1-3) (Figure 1). With regard to the subitems in PDSS, compared with controls, almost all the subitems were significantly impaired in PD patients except for item 2 (sleep onset insomnia), item 11 (painful muscle cramp), and item 14 (refreshment after sleep), and both groups had the most severe ratings in item 3 (sleep maintenance insomnia) and item 8 (nocturia) (Figure 2). Patients with HY 4 had significantly worse scores on item 1 (quality of sleep), item 3 (sleep maintenance insomnia), item 6 (distressing dream), item 11 (painful muscle cramps), and item 15 (daytime dozing) than those with HY 1-3 (Figure 3). In addition, sleep disturbances as measured by the total PDSS score were associated with a longer disease duration, depressive symptoms, and complications in the dopaminergic treatment (dyskinesia and wearing off) [29]. When dividing the PD patients into patients with and without depressive symptoms, we found that patients with depressive symptoms (Zung Self-Rating Depression Scale, SDS score $\geq 40$ ) had significantly impaired scores in almost all PDSS items except item 2 (difficulty in initiating sleep) and item 11 (painful muscle cramps) compared with patients without depressive symptoms and controls [31]. The lack of significant differences between controls and nondepressed patients in PDSS subitems suggests that depressive symptoms play an important role in nocturnal disturbances in PD (Figure 4). From a detailed evaluation of nocturnal symptoms, it was determined that early morning tremor (item 13) and nocturnal dystonia (item 12) were closely associated with depressive symptoms.

In contrast, untreated PD patients can manifest various nocturnal symptoms as assessed by PDSS, such as nocturia, nighttime cramps, dystonia, and tremor [32], emphasizing that nocturnal disturbances should be recognized and managed early even in the early stage of PD.

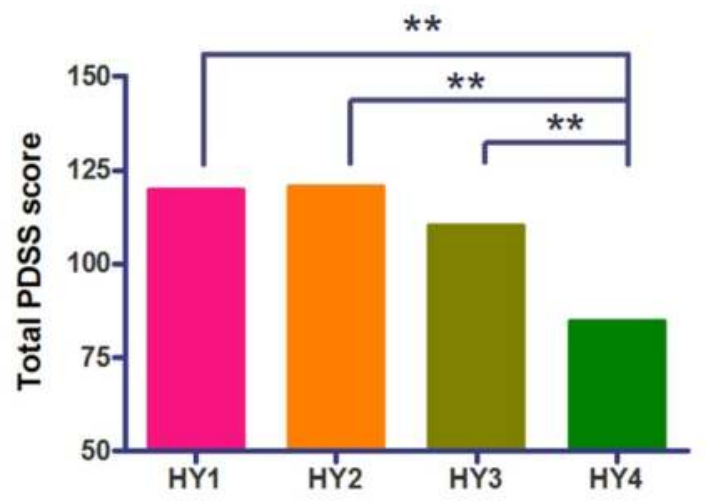

${ }^{*} p<0.05,{ }^{* *} p<0.01$. Bonferroni test after adjustment for age. PD patients with HY stage 4 had a lower score compared with those with HY stages 1 to 3.

Figure 1. Total PDSS score classified by H\&Y stage in patients with PD [29]. 


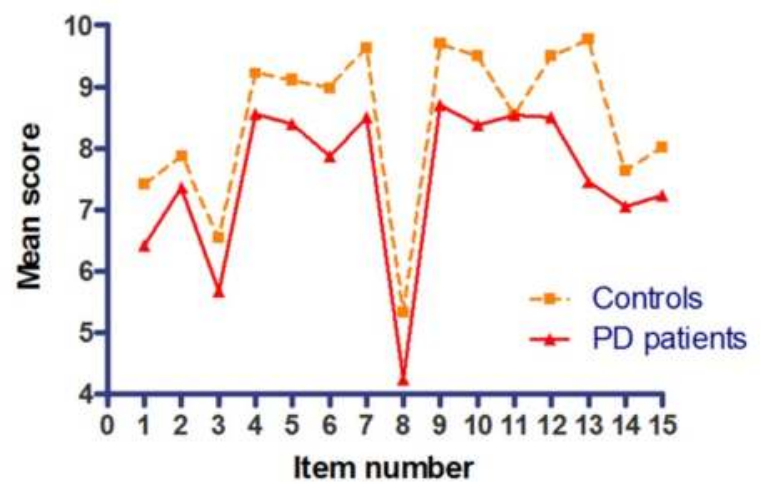

PD patients had a lower score on almost all PDSS scores compared with controls except for items 2 (sleep onset insomnia), 11 (painful muscle cramps), and 14 (tired and sleepy after waking).

Figure 2. PDSS subitems in patients with PD and controls [29].

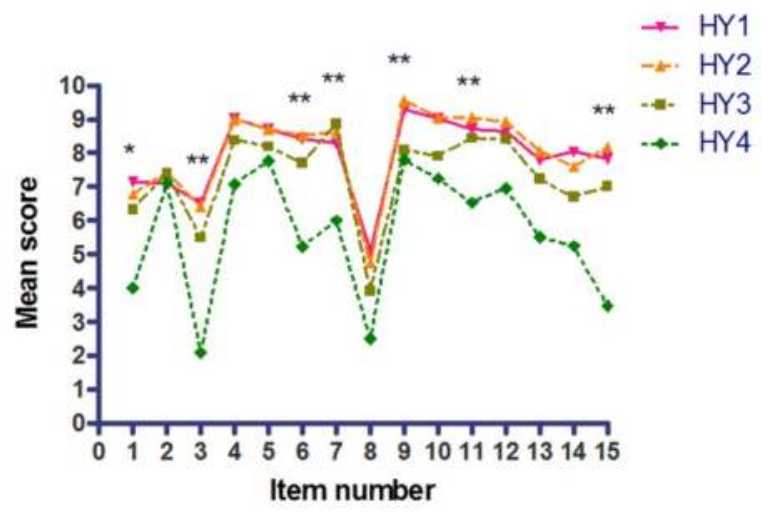

$\overline{{ }^{*} p<0.05,{ }^{* \star} p<0.01}$. One-way ANOVA followed by a Bonferroni test. Compared with patients with HY stages 1-3, PDSS subitems in patients with HY stage 4 were lower for difficulty staying asleep (item 3), nightmares (item 6), painful muscle cramps (item 11), and daytime sleepiness (item 15).

Figure 3. PDSS subitems classified by HY stage in patients with PD [29]. 


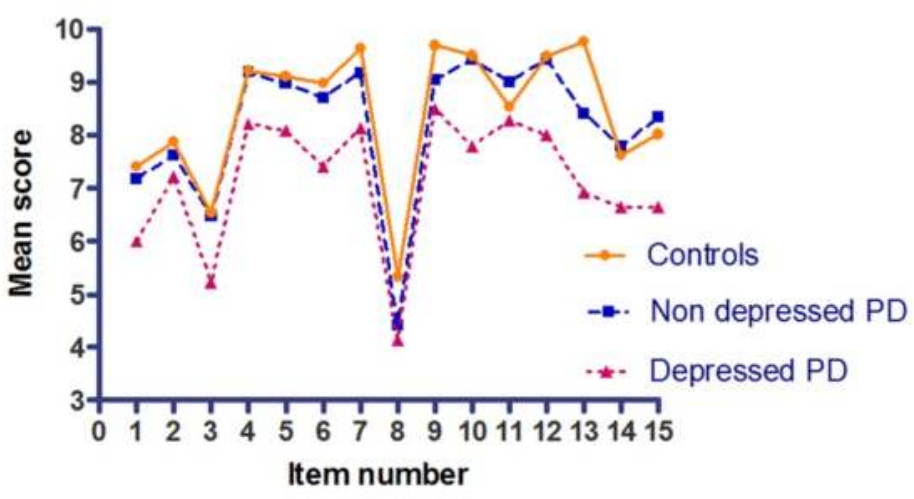

Significant differences in PDSS subitems, except items 2 (sleep onset insomnia) and 11 (painful muscle cramps), are observed among depressed patients, nondepressed patients, and controls.

Figure 4. PDSS subitems in depressed PD, nondepressed PD, and controls [31].

\subsubsection{Parkinson's disease sleep scale-2}

Trenkwalder et al have recently published the PDSS-2, a revised version of the PDSS, to address the frequency of nocturnal symptoms observed in PD patients [33]. A visual analog scale used in the original version of PDSS was transformed into a frequency measure in the PDSS-2. A question regarding daytime sleepiness (item 15 in PDSS) was removed because it reflects complex regulation in PD, and a screening question for SAS was added instead. The PDSS-2 consists of 15 questions about various sleep and nocturnal disturbances rated by the patients using one of five categories, from 0 (never) to 4 (very frequent). Unlike the PDSS, in which a lower score represents worse conditions in sleep, the PDSS-2 total score ranges from 0 (no disturbance) to 60 (maximum nocturnal disturbance) (Figure 5). The study showed satisfactory internal consistency, stability, construct validity, and precision for the PDSS-2 [33]. Nocturnal problems assessed by the PDSS-2 total score were correlated with impaired quality of life and motor impairment. The factor analysis of PDSS resulted in three domain scales: 1) motor problems at night; 2) PD symptoms at night, representing disease-specific symptoms; and 3) disturbed sleep, representing sleep-specific disturbances (Table 3). We have performed a validation study and confirmed the usefulness of the Japanese version of the PDSS-2 [34]. PD patients had significantly impaired scores for the PDSS-2 total score compared with control subjects $(15.0 \pm 9.7$ vs. 9.1 $\pm 6.6, \mathrm{p}<0.001)$ (Figure 6). Significant differences were found between PD patients and controls in three PDSS-2 domain scores and subscores (Figure 7). The PDSS-2 total score was correlated with the Pittsburgh Sleep Quality Index (PSQI), Epworth Sleepiness Scale (ESS), Beck Depression Inventory-II (BDI-II), Parkinson Fatigue Scale (PFS), Parkinson's Disease Questionnaire (PDQ-39) summary index, all of the PDQ-39 domains, and the Unified Parkinson's Disease Rating Scale part III (motor function). The PDSS-2 is simple and easy to use at the outpatient clinic or bedside and is suitable for assessing not only the current status 
on sleep but also evaluating treatment response [35]. For further improvement in the PDSS-2, subitems for the screening for RLS (items 4 and 5) and RBD (item 6) may not be sufficient to differentiate those conditions from RLS mimics, psychosis, and delirium. Adding a subjective evaluation of severity for each item may be useful.

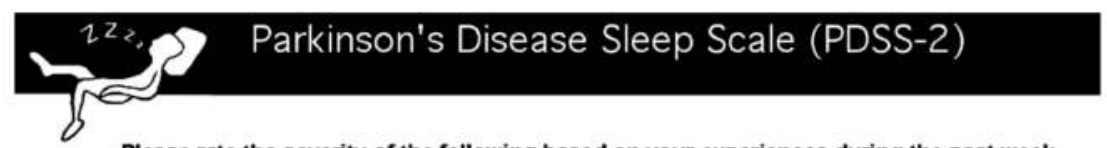

Please rate the severity of the following based on your experiences during the past week (7 days). Please make a cross in the answer box

\begin{tabular}{|c|c|c|}
\hline ten & Often & times \\
\hline $\begin{array}{c}\text { (This means } 6 \\
\text { to } 7 \text { days a } \\
\text { week) }\end{array}$ & $\begin{array}{c}\text { (This means } 4 \\
\text { to } 5 \text { days a } \\
\text { week) }\end{array}$ & $\begin{array}{c}\text { This means } 2 \\
\text { to } 3 \text { days a } \\
\text { week) }\end{array}$ \\
\hline
\end{tabular}

1) Overall, did you sleep well during the last week?

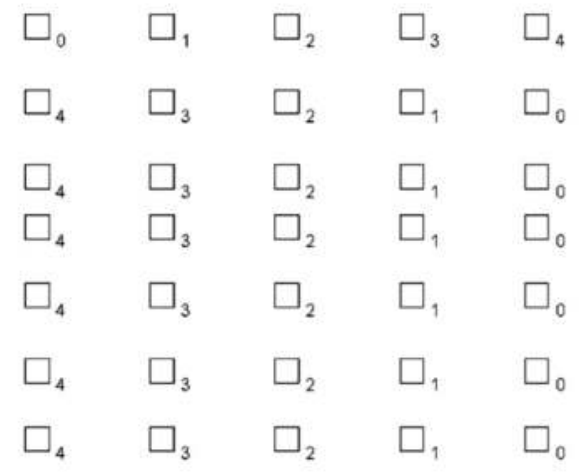

Did you suffer from distressing hallucinations at night (seeing or hearing things that you are told do not exist)?

8) Did you get up at night to pass urine?

9) Did you feel uncomfortable at night because you were unable to turn around in bed or move due to immobility?

10) Did you feel pain in your arms or legs which woke you up from sleep at night?

11) Did you have muscle cramps in your arms or legs which woke you up whilst sleeping at night?

12) Did you wake early in the morning with painful posturing of arms and legs?

13) On waking, did you experience tremor?

14) Did you feel tired and sleepy after waking in the morning?

15) Did you wake up at night due to snoring or difficulties with breathing?
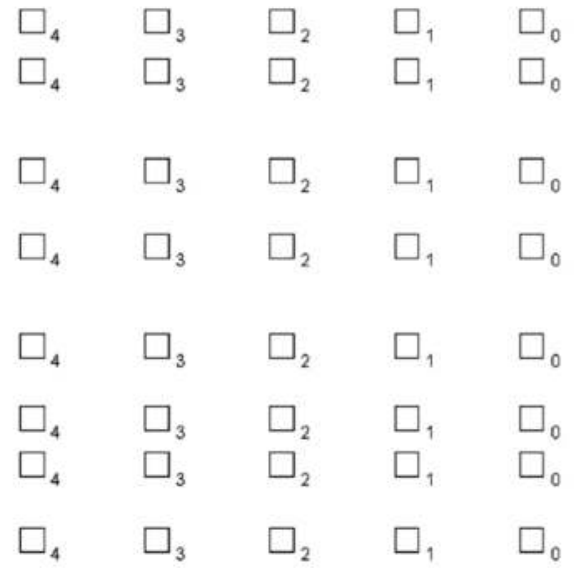

$\overline{\text { Total score ranges }}$ from 0 (no disturbance) to 60 (maximum nocturnal disturbance).

Figure 5. PDSS-2 (reproduced with permission from [33]). 


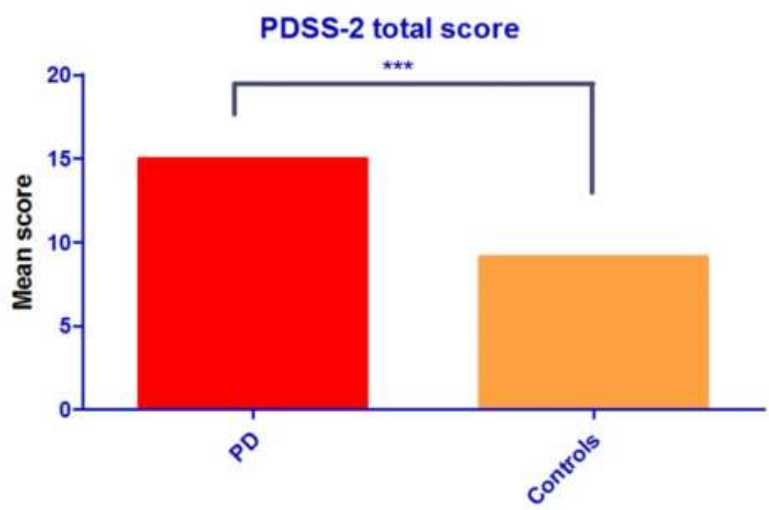

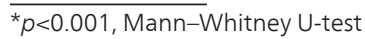

Figure 6. PDSS-2 total score in PD patients and controls

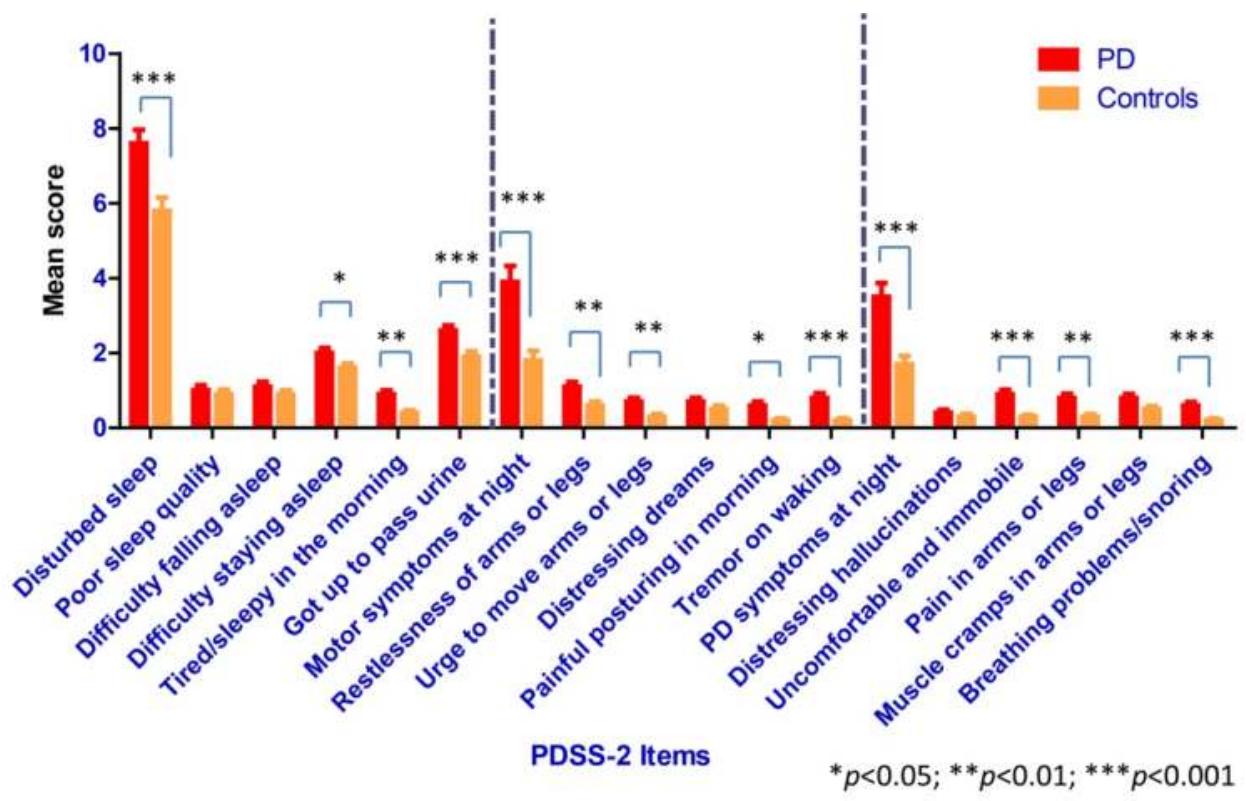

Figure 7. The mean PDSS-2 scores in the three domains between PD patients and controls 


\begin{tabular}{lll}
\hline & PDSS-2 & Item \\
\hline Disturbed sleep & & \\
\hline Poor sleep quality & 2 \\
\hline Difficulty falling asleep & 3 \\
\hline Difficulty staying asleep & 14 \\
\hline Tired/sleepy in the morning & 8 \\
\hline Get up to pass urine & \\
Motor symptoms at night & 4 \\
\hline Restlessness of arms or legs & 5 \\
\hline Urge to move arms or legs & 6 \\
\hline Distressing dreams & 12 \\
\hline Painful posturing in morning & 13 \\
\hline Tremor on waking & \\
\hline PD symptoms at night & 7 \\
\hline Distressing hallucinations & 9 \\
\hline Uncomfortable and immobile & 10 \\
\hline Pain in arms or legs & 11 \\
\hline Muscle cramps in arms or legs & 15 \\
\hline Breathing problems/snoring & \\
\hline
\end{tabular}

Table 3. PDSS-2 domain scale

\section{Nocturnal problems in PD}

The significant impact of nocturnal problems in PD patients has been emphasized by the study by Lees et al [4], which found that among 220 patients with PD, 215 (98\%) reported sleep problems, and $29 \%$ took hypnotics or sedatives, but only $6 \%$ took any anti-parkinsonian drug during the night (Table 4). In the study using continuous activity monitoring, compared with the healthy elderly subjects, patients with PD showed an elevated nocturnal activity level and an increased proportion of time with movement [36]. Nocturnal motor symptoms such as worsened rigidity, tremor, dystonia, and akinesia can lead to nocturnal awakening and sleep maintenance insomnia, a common form of insomnia in PD [4, 7, 24, 29, 37]. Sleep-onset insomnia does not seem to account for the majority of insomnia cases in PD when compared with age-matched controls. In a community-based sleep study by Tandberg et al, sleep-onset insomnia, sleep-maintenance insomnia, and early awakening were observed in $31.8 \%, 38.9 \%$, and $23.4 \%$ of PD patients compared with $22 \%, 12 \%$, and $11 \%$ of healthy controls, respectively [7]. The frequency of sleep onset insomnia did not significantly differ between the groups. Selfreported sleep problems occurred significantly more often in patients with PD $(60 \%)$ than in healthy controls (33\%) and patients with diabetes mellitus (45\%). Our cross-sectional studies have also found sleep-maintenance insomnia, but not sleep-onset insomnia, to be significantly more prevalent in patients with PD than in controls [29, 34]. Sleep disturbances correlate with motor impairment in PD patients [6]. However, even in untreated patients with PD, in addition to the changes in sleep architecture, motor symptoms may predominately occur at night rather 
than during the day [32]. Therefore, nocturnal motor symptoms can interfere with sleep and are not always parallel with daytime motor symptoms, which is supported by several studies showing a weak or nonexistent correlation between sleep disturbances and daytime motor symptoms (UPDRS motor score) [7,38] and no correlation between nocturnal motor symptoms obtained by PDSS-2 and UPDRS motor scores [33]. In patients with an early to moderate stage of PD, a substantial number of patients may suffer from nocturnal problems; however, this may be missed in clinical practice unless physicians screen for it.

An international cross-sectional study comprising 242 patients with PD (HY 2 (n=121) being most frequent) revealed that a significant number of sleep-related symptoms were undeclared by patients before the administration of the non-motor questionnaire: nocturia, $43.9 \%$; daytime sleepiness, 52.4\%; insomnia, 43.9\%; vivid dreams, 52.4\%; acting out during dreams, $44.1 \%$; and restless legs, 36.4\% [39]. Patients in the advanced stages of the disease have motor dysfunction throughout the day; therefore, its impact on the nighttime period should always be considered.

\begin{tabular}{lcc}
\hline Symptoms & Experienced by (\%) & Most troublesome (\%) \\
\hline Need to visit lavatory & 79 & 29 \\
Inability to turn over in bed & 65 & 39 \\
Painful leg cramps & 55 & 15 \\
Vivid dreams / nightmares & 48 & 9 \\
Inability to get out of bed unaided & 35 & 15 \\
Limb or facial dystonia & 34 & 10 \\
Back pain & 34 & 9 \\
Jerks of legs & 33 & 5 \\
Visual hallucinations & 16 & 3 \\
None & 4 & \\
\hline
\end{tabular}

Table 4. Nocturnal problems in PD patients (adapted from Lees et al [4])

Although nocturia is associated with normal aging, $80 \%$ of PD patients show two or more episodes of nocturia per night resulting from overflow incontinence and a spastic bladder [4].Urinary bladder-related symptoms, such as frequency, urgency, and urge incontinence, are common in PD, resulting in frequent nocturnal awakenings. In animal studies, the stimulation of D1 receptors inhibits the micturition reflex, whereas the stimulation of D2 receptors facilitates the micturition reflex. D2 depletion of dopaminergic neurons induces an overactive bladder, and D1 receptor agonists produce a dose-dependent inhibition of the micturition reflex [40]. For the treatment of nocturia, first, a urologic examination is recommended to rule out underlying urologic diseases. Switching from bromocriptine to pergolide improved nocturia, thereby improving sleep status in patients with PD [41]. Anticholinergic drugs, such as oxybutynin and tolterodine, are commonly used for detrusor hyperreflexia. Subthalamic deep brain stimulation improved detrusor hyperreflexia [42]. When nocturia is related to wearing-off symptoms, adding a long-acting dopamine agonist before bedtime should be considered. 
Pain has been reported in approximately $60 \%$ of PD patients [43] in association with sleep disturbances and depressive symptoms [44, 45], in addition to tremor, rigidity, akinesia, dystonia, and akathisia. Pain is classified into the following categories: musculoskeletal pain, radicular or neuropathic pain, dystonia-related pain, akathitic discomfort, and primary central parkinsonian pain [46]. Nocturnal pain is related to nocturnal awakening. To evaluate whether pain is related to wearing off is important because it can worsen during wearing-off periods. Primary central parkinsonian, akathitic, and dystonia-related pain may respond to dopaminergic treatment.

Increased severity in nocturnal motor symptoms such as rigidity, bradykinesia, and resting tremor may benefit from increasing the bedtime dose of dopaminergic treatment. A doubleblinded, placebo-controlled trial demonstrated the efficacy of 24-h rotigotine on daytime motor function (UPDRS part III) and nocturnal disabilities, as evaluated by the PDSS-2 [35]. Subcutaneous overnight apomorphine infusion markedly reduced nocturnal awakenings, nocturnal off periods, pain, dystonia, and nocturia [47]. High-frequency subthalamic nucleus stimulation in 10 PD patients with insomnia reduced nighttime akinesia by $60 \%$ and completely suppressed axial and early-morning dystonia [48]. Furthermore, a 24-week, double-blind study showed that once-daily ropinirole prolonged release improved nocturnal symptoms (as assessed by PDSS) in patients with advanced PD who were not optimally controlled with levodopa and suffered troublesome nocturnal disturbances [49]. In contrast, some studies indicate that dopaminergic drugs can have alerting effects, possibly interfering with sleep continuity in patients with PD $[14,36,50]$.

Hallucinations and psychosis affect 30 to $45 \%$ of PD patients who have been treated with levodopa for a long period [51]. Among a wide spectrum of hallucinations, visual hallucinations are commonly observed. Sleep disturbances, daily levodopa doses, older age, depression, and cognitive impairment are associated with an increased risk for hallucinations in PD patients $[52,53]$. In contrast to nocturnal motor symptoms, nocturnal psychiatric symptoms including hallucination and psychosis can be effectively treated by reducing the bed time dose of dopaminergic treatment or adding antipsychotics.

The prevalence of depression in PD patients varies, ranging from 2.7\% to 89\% [54]. Depression is associated with sleep disturbances and impaired quality of life in patients with PD [55, 56]. Nortripryline, desipramine, and selective serotonin reuptake inhibitors (venlafaxine and paroxetine) are more effective than placebo in treating depression in PD [57]. Additionally, it should be noted that depressive symptoms worsen during wearing-off periods and also contribute to worsened motor symptoms [58]. In this regard, antiparkinsonian drugs show beneficial effects not only on motor symptoms but also on a patient's mood. Pramipexole improved depressive symptoms in patients with PD mainly through a direct antidepressant effect rather than through improved motor symptoms [59].

Untreated nocturnal disturbances contribute not only to sleep fragmentation but also to daytime sleepiness and thus daytime motor dysfunction. The primary sleep disorders include RBD, RLS, and SAS, all of which should be properly managed because of their clinical significance in disease. RBD is a REM parasomnia characterized by loss of muscle atonia during 
REM sleep and complex motor behavior in association with dream content [60]. Table 5 summarizes the management of sleep problems in PD.

\begin{tabular}{|c|c|c|}
\hline Type of insomnia & Cause & Treatment \\
\hline \multirow[t]{2}{*}{ Difficulty initiating sleep } & Unknown cause & $\begin{array}{l}\text { Hypnotics (short-acting type; zolpidem, } \\
\text { zopiclone, eszopiclone, brotizolam) }\end{array}$ \\
\hline & Drug related (alerting effect) & Remove or reduce dose of causative drug \\
\hline \multirow{5}{*}{$\begin{array}{l}\text { Difficulty maintaining sleep / early } \\
\text { morning awakening }\end{array}$} & Unknown cause & Hypnotics (intermediate type; flunitrazepam) \\
\hline & $\begin{array}{l}\text { Wearing off, resting tremor, } \\
\text { rigidity, akinesia, }\end{array}$ & $\begin{array}{l}\text { Increase frequency of levodopa administration, } \\
\text { add dopamine agonist, or switch to a different } \\
\text { type of dopamine agonist }\end{array}$ \\
\hline & Drug-induced dyskinesia & $\begin{array}{l}\text { Increase frequency of levodopa and reduce } \\
\text { dose of levodopa administration, add } \\
\text { dopamine agonist }\end{array}$ \\
\hline & Depression, anxiety & $\begin{array}{l}\text { Antidepressant (SSRI, SNRI, tricyclic } \\
\text { antidepressant) } \\
\text { Anti-anxiety drug } \\
\text { Dopamine agonist (D3 R) }\end{array}$ \\
\hline & Nocturia & $\begin{array}{l}\text { Oxybutynin, flavoxate } \\
\text { Dopamine agonist (D1 R) }\end{array}$ \\
\hline \multirow[t]{3}{*}{ Excessive daytime sleepiness } & Unknown cause & Daytime rehabilitation \\
\hline & Drug related (sedative effect) & $\begin{array}{l}\text { Remove or reduce dose of causative drug } \\
\text { (including dopamine agonist) }\end{array}$ \\
\hline & Refractory & Modafinil, caffeine \\
\hline Hallucination, delusion, delirium & & $\begin{array}{l}\text { Reduce dopaminergic drugs, consider Yi-Gan } \\
\text { San and atypical antipsychotics }\end{array}$ \\
\hline REM sleep behavior disorder & & $\begin{array}{l}\text { Hazard avoidance (remove potentially } \\
\text { dangerous objects from the bedroom and } \\
\text { place a mattress on the floor), consider } \\
\text { clonazepam and Yi-Gan San }\end{array}$ \\
\hline Sleep apnea syndrome & & $\begin{array}{l}\text { Continuous positive airway pressure therapy } \\
\text { (severe case) }\end{array}$ \\
\hline \multicolumn{2}{|c|}{ Restless legs syndrome, periodic limb movement disorder } & $\begin{array}{l}\text { Adjustment of dopaminergic treatment, use } \\
\text { dopamine agonist before bedtime, consider } \\
\text { iron supplement (if serum ferritin are below } 50 \\
\mu \mathrm{g} / \mathrm{L} \text { ) and clonazepam }\end{array}$ \\
\hline
\end{tabular}

Table 5. Management of sleep problems in PD 


\section{Excessive daytime sleepiness and sudden-onset sleep episodes}

Excessive daytime sleepiness (EDS) occurs in approximately $15 \%-50 \%$ of PD patients [61-63]. A high Epworth sleepiness scale (ESS) score, male gender status, longer disease duration, and high disease severity and dopaminergic medication have been associated with EDS [61, 62, 64]. Multifactorial nocturnal problems (Table 1) are the causes of sleep disturbances in PD and also lead to EDS, reflecting poor sleep quality and duration. In addition to nocturnal problems, PD-related pathological changes play a role in sleepiness: an impaired arousal system has been suggested in PD (Table 6; Figure 8). A subset of patients with PD exhibit EDS and a sudden onset of sleep episodes with a short sleep latency and a short sleep-onset REM period, independent of the nighttime sleep conditions. This finding suggests a narcolepsy phenotype in PD patients. Narcolepsy is a sleep disorder characterized by severe daytime sleepiness, cataplexy, hypnagogic hallucination, and sleep paralysis caused by loss of orexin neurons. However, cataplexy is lacking in patients with PD [65], and orexin levels in the cerebrospinal fluid in PD patients with EDS remains controversial [66-68]. Decreased orexin levels in the hypothalamus and a loss of orexin neurons have been observed in PD patients in correlation with clinical disease progression; however, no description was provided for EDS [69, 70].

Dopaminergic medication, i.e., taking dopamine agonists or levodopa, is associated with increased daytime sleepiness in patients with PD [61, 62, 64, 71, 72]. Although a higher levodopa equivalent dose is correlated with increased daytime sleepiness in PD [62, 64, 71], the association between the specific type of dopamine agonist and EDS is unclear [61, 62, 72, 73] (Figure 9). Untreated PD patients do not seem to have EDS compared with controls [22, 74]. However, the study consisting of 3078 men aged 71 to 93 years showed that there was more than a threefold excess (odds ratio 3.3 ) in the risk of PD in men with EDS versus men without EDS [75]. In a prospective study, of the 232 patients included at baseline, 138 were available for reevaluation after 4 years, and 89 patients were available after 8 years. The EDS frequency increased from $5.6 \%$ at the baseline to $22.5 \%$ at the 4 -year follow up and $40.8 \%$ at the 8-year follow up. EDS was related to age, gender, and use of dopamine agonists in the logistic regression model, whereas in patients never having used dopamine agonists, hypersomnia was associated with the HY stage only, suggesting that age- and disease-related disturbances of the sleep-wake regulation contribute to hypersomnia in PD and that treatment with dopamine agonists also contribute to EDS [76]. Regarding the interaction between dopamine and sleep [77], the D1 receptor agonist promotes wakefulness and decreases slowwave sleep and REM sleep. In contrast, the D2 receptor agonist has a biphasic action: a lower dose reduces wakefulness and increases slow-wave sleep and REM sleep via the pre-synaptic auto D2 receptor, whereas a higher dose stimulates wakefulness via the post-synaptic D2 receptor. D3 receptor stimulation increases slow-wave sleep and promotes sleep. This result for D2 receptor stimulation differs from that observed in patients with PD: a higher dose of dopaminergic drugs is associated with EDS. Bliwise et al reported that increasing dosages of dopamine agonists were associated with less daytime alertness, whereas higher levels of levodopa were associated with higher levels of alertness [78]. 
Sudden-onset sleep episodes while driving have been reported in 3.8\%-22.8\% of PD patients and are associated with a high score on the ESS [61, 64,73], although sleepiness is sometimes unrecognized by patients. However, similar to the findings by Tan et al, which showed that ESS scores $\geq 10$ had a $71.4 \%$ sensitivity and $88.4 \%$ specificity for predicting a sleep attack [64], our study showed that an ESS score of $\geq 10$ had a $75 \%$ sensitivity and $82.4 \%$ specificity for predicting sleep episodes [62]. This evidence suggests that PDS patients with EDS have a significant increased risk for sudden-onset sleep episodes.

\begin{tabular}{lcc}
\hline Nucleus & Main neurotransmitter & Neuronal loss in Parkinsonian brain (\%) \\
\hline Locus coeruleus & Noradrenaline & $40-50$ \\
Median raphe & Serotonin & $20-40$ \\
Ventral periaqueductal gray matter & Dopamine & 9 \\
Pedunculopontine nucleus & Acetylcholine & 57 \\
Tuberomammillary nucleus & Histamine & Unchanged enzymatic activity \\
Lateral hypothalamus & Orexin (hypocretin) & $23-62$ \\
Basal forebrain & Acetylcholine & $32-93$ \\
\hline
\end{tabular}

Table 6. Neuronal loss in arousal systems in the brains of patients with PD (adapted from [79]).

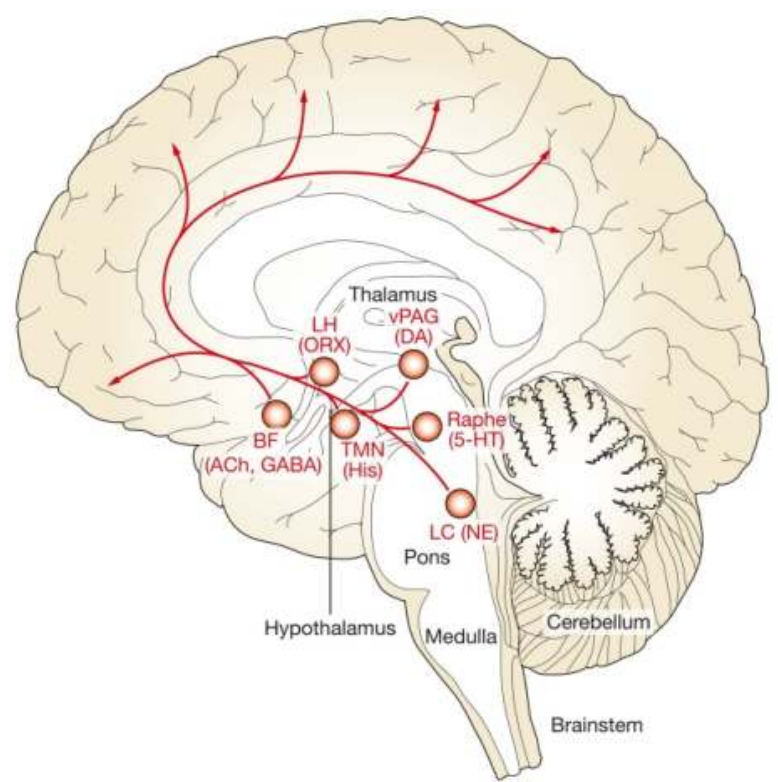

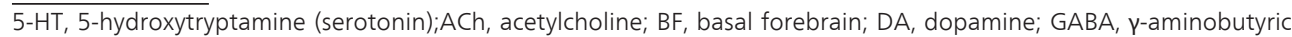
acid; His, histamine; LC, locus ceruleus; LH, lateral hypothalamus; NE, norepinephrine; ORX, orexin; Raphe, median raphe nucleus; TMN, tuberomamillary nucleus; vPAG, ventral periaqueductal gray matter.

Figure 8. The ascending arousal systems in the human brain (reproduced with permission from [80]). 


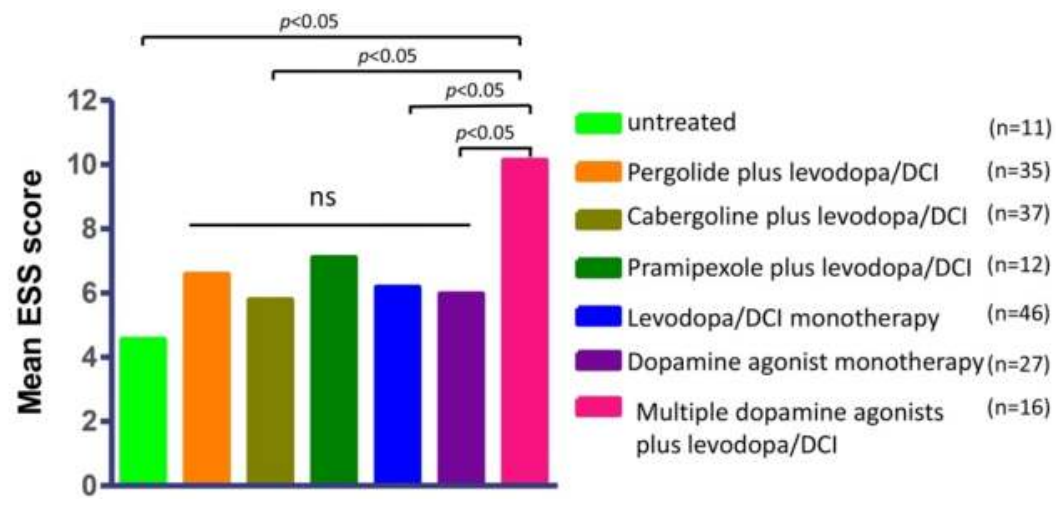

The ESS score is significantly higher in the group with multiple dopamine agonists plus levodopa/DCl; however, no differences in EDS among different types of dopamine agonist groups are shown.

Figure 9. Excessive daytime sleepiness and dopamine agonists in patients with PD (created based on the data from [62]).

\section{Primary sleep disorders}

\subsection{Rapid eye movement sleep behavior disorder}

REM sleep behavior disorder (RBD) is characterized by a loss of muscle atonia during REM sleep, resulting in dream-enacting behavior, leading to injury to the individual or bed partner [81]. The important implication is that idiopathic RBD patients are found to be at high risk of later developing neurodegenerative diseases in the synucleinopathies, such as PD, multiple system atrophy, and dementia with Lewy bodies [82]. Schenck and colleagues first reported that $3.7 \pm 1.4$ years after an initial diagnosis of idiopathic RBD, $38 \%$ of patients developed a parkinsonian syndrome [83]. In a prospective study of idiopathic RBD patients, the estimated 5 -year risk of neurodegenerative disease was $17.7 \%$, the 10 -year risk was $40.6 \%$, and the 12 year risk was $52.4 \%$ [84]. A recent clinicopathological study of 172 cases of RBD with or without coexisting neurological diseases revealed that among the neurodegenerative disorders associated with RBD ( $\mathrm{n}=170), 160$ (94\%) were synucleinopathies [85]. The association between RBD and synucleinopathy was particularly high when RBD preceded the onset of other neurodegenerative syndrome features. Before the onset of motor symptoms, idiopathic RBD subjects already possess characteristics, such as olfactory impairment, impaired color vision, autonomic dysfunction, mild cognitive impairment, a decreased uptake of cardiac (123) Imetaiodobenzylguanidine (MIBG), and hyperechogenicity in the substantia nigra [86-90], that are similar to PD. These may be potential predictive markers for future development of PD. In the subjects with idiopathic RBD who were initially free of neurodegenerative disease, the severity of the REM atonia loss on the baseline PSG findings was associated with the development of PD [91]. Employing noninvasive imaging techniques such as transcranial sonography, single-photon emission computed tomography, and positron emission tomography may be helpful in identifying patients with iRBD potentially at future risk for PD [92]. 
Lesions of the locus coeruleus perialpha in cats and of the sublaterodorsal nucleus in rats have been shown to cause REM sleep without atonia with complex movements [93,94]. The equivalent of these nuclei in humans is the subcoeruleus nucleus in the pons, which is first affected during the early stages of PD. In addition, other brainstem nuclei such as the cholinergic nuclei, pedunculopontine nucleus, and laterodorsal tegmental nucleus also play a role in regulating REM sleep [95]. In the study using neuromelanin-sensitive imaging, reduced signal intensity is found in the locus coeruleus/subcoeruleus area in patients with PD relative to controls, and that difference is more marked in patients with PSG-confirmed RBD than in those without RBD. A reduced signal intensity in those areas is found to be correlated with the percentage of abnormally increased muscle tone during REM sleep. This study first shows the involvement of the coeruleus/subcoeruleus complex in PD patients and, more markedly, in those with concomitant RBD [96].

The frequency of RBD is reported to be $15-60 \%$ of PD patients (Table 7) [79]. Co-occurrence of RBD in PD may represent distinct characteristics of PD: akinetic rigid phenotype, an increased frequency of falls, and a poor response to dopaminergic medications, orthostatic hypotension, and impaired color vision have been described compared with PD patients without RBD [97, 98]. A decreased uptake of cardiac MIBG is also reported in PD patients with RBD compared with those without RBD $[99,100]$. In a prospective study with 42 patients with PD (27 patients with PSG-confirmed RBD and 15 patients without RBD) for 4 years, 48\% with RBD developed dementia, compared with $0 \%$ of those without RBD, suggesting that RBD was associated with an increased risk of dementia in patients with PD [101]. Similarly, Nomura et al found coexistence of clinical RBD, but not subclinical RBD, was associated with the development of dementia in PD. In their study, RBD, but not subclinical RBD, was associated with orthostatic hypotension and levodopa equivalent dose equivalents in patients with PD [102].

With respect to the clinical motor subtype, not all the studies support the akinetic rigid phenotype as the clinical phenotype associated with PD-RBD. A study of 457 PD patients with sleep disturbances did not find a characteristic clinical subtype for PD with RBD but did report a higher disease severity and longer disease duration in PD patients with RBD than in those without [103]. In early PD (disease duration $\leq 5$ years and HY stage $1-2.5$ ), the RBD comorbidity (confirmed by clinical history during the preceding 6 months and a cut-off score $>$ 4 on the RBD screening questionnaire) was significantly higher (55\%) in PD patients, but clinical subtype and disease severity did not differ between patients with and without RBD [104]. It has been reported that a tremor-dominant type may transition into a non-tremor dominant type over time and with increased age [105]. In our study including 93 patients with PD and controls using the Japanese version of the RBD screening questionnaire (RBDSQ-J)

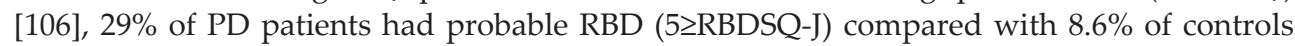
[107]. Patients with probable RBD had a higher score of PDQ-39 cognition and emotional wellbeing and more frequent sleep onset insomnia, distressing dreams, and hallucinations. However, there were no differences between these two groups with respect to the clinical subtype, disease severity, or motor function. In the study consisting of 57 newly diagnosed drug-naïve patients with PD, 17 PD patients (30\%) were diagnosed with RBD by overnight PSG. Non-RBD patients and RBD patients did not differ with respect to age, gender, disease duration, motor symptom subtype and severity, and cognitive performance. PSG parameters such as total sleep time, REM sleep percentage, apnea-hypopnea index, and mean oxygen 
saturation also did not differ [108]. Differences in clinical background factors between PD patients with and without RBD await confirmation in longitudinal studies. Interestingly, restored motor control (movements, speech, and facial expressions) during REM sleep with enacted dreams has been reported in PD patients with RBD [109].

Before starting treatment of RBD, it should be noted that RBD can be triggered or worsened by antidepressants [110]. Clonazepam $(0.5$ to $1.5 \mathrm{mg})$ at bed time is the most effective treatment for RBD patients. Melatonin (3-12 mg) at bedtime has been shown to ameliorate RBD [111, 112]. Administration of Yi-Gan San, an herbal medication, at $2.5 \mathrm{~g}$ three times a day, alone or in conjunction with $0.25 \mathrm{mg}$ clonazepam, may also be effective [113]. Some patients may respond to 1 evening or bedtime dose of $2.5 \mathrm{~g}$.

\begin{tabular}{|c|c|c|}
\hline DISEASE & PREVALENCE (\%) & \\
\hline & RBD & RWA \\
\hline \multicolumn{3}{|l|}{ Synucleinopathies } \\
\hline Parkinson's disease & $15-60$ & \\
\hline Multiple system atrophy & 90 & \\
\hline Dementia with Lewy bodies & 86 & \\
\hline \multicolumn{3}{|l|}{ Tauopathies } \\
\hline Progressive supranuclear palsy & $10-11$ & $0-33$ \\
\hline Alzheimer's disease & 7 & 29 \\
\hline Corticobasal degeneration & Case reports & \\
\hline Frontotemporal dementia & None & \\
\hline Pallidopontonigral degeneration & 0 & 0 \\
\hline Guadeloupean parkinsonism & 78 & \\
\hline \multicolumn{3}{|l|}{ Genetic Diseases } \\
\hline Huntington's disease & 12 & \\
\hline Spinocerebellar ataxia type 3 & 56 & \\
\hline Parkin mutation & 60 & \\
\hline
\end{tabular}

RBD, REM sleep behavior disorder; RWA, REM sleep without atonia

Table 7. RBD in neurodegenerative diseases (adapted from [79])

\subsection{Restless leg syndrome}

RLS is characterized by an urge to move the legs, uncomfortable leg sensations, and motor restlessness, typically occurring during the evening and night. The pathogenesis of RLS remains unclear; however, dysfunction of the dopaminergic A11 nucleus of the hypothalamus has been implicated [114]. The hypothalamic A11 nucleus has projections to the suprachiasmatic nuclei and dorsal raphe, and it provides descending projections to the preganglionic sympathetic neurons, dorsal horn region, interneurons, and somatic motor neurons [114]. Neurophysiological studies have revealed disinhibition of inhibitory cortical controls, decreased intracortical inhibition, and hyperexcitability of spinal pathways [115-117]. In view 
of a marked beneficial response to dopaminergic treatment observed in both PD and RLS, a shared dopaminergic dysfunction has been suggested in PD and RLS [118]. However, unlike $\mathrm{RBD}$, there is no evidence suggesting RLS as a risk factor of PD, and the co-morbidity of RLS in PD patients varies widely from 0 to 50\% [119]. In contrast to PD, which shows degeneration of the striatonigral dopaminergic neurons, confirmed by the reduced striatal uptake observed in neuroimaging studies, in idiopathic RLS, PET/SPECT studies have not produced consistent findings of striatonigral dopaminergic dysfunction [120, 121]. Postmortem studies of RLS patients have found an increased total and phosphorylated tyrosine hydroxylase in the putamen and substantia nigra [122]. Cerebrospinal fluid iron insufficiency has been demonstrated in idiopathic RLS independent of serum iron levels [123, 124]. The transcranial sonography findings of substantia nigra hypoechogenicity and brain imaging studies also suggest brain iron insufficiency in RLS patients [125, 126]. In contrast, the hyperechogenicity in the substantia nigra commonly observed in patients with PD may reflect increased levels of iron in the substantia nigra. No difference in the substantia nigra echogenicity has been reported between the PD with RLS and PD without RLS groups [127]. Thus, there are some similarities between PD and idiopathic RLS, including a marked response to dopamine agonist treatment, although the two disorders may have different pathogenic mechanisms [118, 128].

In PD, there are several conditions that mimic RLS, including sensory symptoms, pain, and the wearing-off phenomenon [118]. Moreover, the clinical overlap between RLS, wearing-offrelated lower limb discomfort, and restlessness and akathisia has been suggested [129, 130]. In the study evaluating RLS in PD, $20.8 \%$ of PD patients had RLS, and patients with PD with RLS had an older age at onset and were much less likely to report a family history of RLS compared with patients with isolated RLS [131]. Complicatedly, dopaminergic treatment may either mask or augment coexisting RLS symptoms in PD [129], and there is an association between long-term dopaminergic treatment and RLS development in PD patients [132].

In addition, in recent studies, an increased frequency of leg motor restlessness (LMR) without fulfilling the criteria for RLS has been described in patients with PD [128]. A total of 200 early, drug-naive patients with PD derived from a population-based incident cohort and 173 ageand gender-matched control subjects were examined, and 31 (15.5\%) of PD patients and 16 (9.2\%) of control subjects met RLS criteria ( $\mathrm{p}=0.07$ ). However, LMR (OR 2.84, 95\% CI 1.43-5.61, $\mathrm{p}=0.001$ ) but not RLS (OR 1.76, 95\% CI 0.90-3.43, p=0.089) occurs with a near 3-fold higher risk in early PD compared with controls [128]. Shimohata and Nishizawa reported that among 158 patients with PD, 11\% had RLS and 19\% had LMR without fulfilling the criteria for RLS (total LMR, 30\%). The frequencies of insomnia and EDS in patients with LMR were lower than those of patients with RLS but higher than in patients without LMR or RLS, highlighting the impact of LMR and RLS on sleep disturbance in PD [133]. Likewise, our study showed that LMR was more frequent in patients with PD than in controls (32.3\% vs. $14.0 \%$; scores of PDSS-2 subitem 4 (restlessness of arms or legs) or subitem 5 (urge to move arms or legs) $\geq 2$ ), although RLS frequency was similar between the patients with PD and controls (5.5\% vs. 2.2\%) [34].

For the treatment of RLS, iron replacement therapy should be considered when the serum levels of ferritin are lower than $50 \mu \mathrm{g} / \mathrm{L}$. Using long-acting dopamine agonists at bedtime is effective. 


\subsection{Sleep apnea syndrome}

Upper airway dysfunction associated with parkinsonism, such as bradykinesia and rigidity, and fluctuations in the respiratory muscles that occur with motor complications can contribute to obstructive sleep apnea in patients with PD [17]. A significant correlation between the apnea hypopnea index (AHI) and the severity of PD was reported [21]. Earlier studies suggested SAS is more frequent in patients with PD than in control subjects [17, 21]. However, in PD patients, lower levels of decline in the minimal or mean nocturnal oxygen saturation levels than in AHImatched controls were observed [17, 21]. In contrast, recent studies suggest that the comorbidity of SAS is not more frequent in PD patients than in the general population, and thus, it may not a relevant issue in PD [10, 11, 134]. Moreover, it has been argued that SAS may not play a major role in EDS in PD. De Cock et al. [11] reported that sleep apnea (defined as an $\mathrm{AHI}>5$ ) was less frequent in the PD group than in the in-hospital control group ( $27 \%$ vs. $40 \%)$; however, PD patients with sleep apnea had greater motor disability than patients without sleep apnea. EDS was not correlated with sleep apnea.

In our questionnaire-based study, snoring was more frequent in PD patients than in controls (14.0\% vs. $1.1 \%)$, and snoring in PD patients was associated with disease severity, impaired motor function, and a decreased quality of life, but it was not associated with EDS [135]. Table 8 shows the previous PSG studies that evaluated sleep-related breathing disorders in PD.

When a patient has severe obstructive SAS, continuous positive airway pressure therapy should be considered.

\begin{tabular}{|c|c|c|c|c|c|c|}
\hline Authors & Year & $\begin{array}{l}\text { Sample No. } \\
\text { PD/Controls }\end{array}$ & $\begin{array}{l}\text { Age (years) } \\
\text { PD/ Controls }\end{array}$ & $\begin{array}{l}\text { ESS score and EDS } \\
\text { PD/Control }\end{array}$ & $\begin{array}{l}\text { Frequency of } \\
\text { SRBD } \\
\text { PD/Controls }\end{array}$ & $\begin{array}{c}\mathrm{AHI}(/ \mathrm{h}) \\
\text { PD/Controls }\end{array}$ \\
\hline $\begin{array}{l}\text { Arnulf et al } \\
\quad[14]\end{array}$ & 2002 & $\begin{array}{c}* 54 \\
(44 \mathrm{M}) / \mathrm{NA}\end{array}$ & $\begin{array}{c}68 \pm 7.0 / \\
\text { NA }\end{array}$ & $\begin{array}{c}\text { ESS; } 14.3 \pm 4.1 / \mathrm{NA} \\
\text { EDS; } 50 \% / \mathrm{NA} \\
\text { (mean } \mathrm{SL}<5 \mathrm{~min} \text { ) }\end{array}$ & $\begin{array}{l}48.1 \% / N A(A H I>5) \\
20 \% / N A(A H I>15)\end{array}$ & NA/NA \\
\hline $\begin{array}{c}\text { Maria et al } \\
{[21]}\end{array}$ & 2003 & $\begin{array}{l}15(12 \mathrm{M}) / \\
15(12 \mathrm{M})\end{array}$ & $63 \pm 4 / 60 \pm 4$ & ESS; $12.3 / 6.1$ & $66.7 \% / N A$ & $11.7 / 5.7$ \\
\hline $\begin{array}{l}\text { De Cock et } \\
\text { al [11] }\end{array}$ & 2010 & $\begin{array}{l}50(35 \mathrm{M}) / \\
50(35 \mathrm{M})\end{array}$ & $\begin{array}{l}62.1 \pm 9.8 / \\
62.4 \pm 13.8\end{array}$ & $\begin{array}{c}\text { ESS; } 9.2 \pm 4.7 / 5.8 \pm 4.0 \\
\text { EDS; } 24 \% / 72 \%(\text { ESS }>10)\end{array}$ & $\begin{array}{c}20 \% / 40 \% \\
(\mathrm{AHI}>5)\end{array}$ & $\begin{array}{l}6 \pm 11 / \\
23 \pm 23\end{array}$ \\
\hline $\begin{array}{l}\text { Trotti et al } \\
\text { [134] }\end{array}$ & 2010 & $\begin{array}{c}* * 55 \\
(37 \mathrm{M}) / 6132\end{array}$ & $\begin{array}{l}63.9 \pm 9.1 / \\
62.9 \pm 11.0\end{array}$ & NA/NA & $\begin{array}{c}43.6 \% / 46.4 \% \\
(\mathrm{AHI}>5)\end{array}$ & $\begin{array}{c}6.3-8.0(9.2-10.6) / \\
\text { NA }\end{array}$ \\
\hline $\begin{array}{l}\text { Buskova et } \\
\text { al [22] }\end{array}$ & 2011 & $\begin{array}{c}\text { \#15 } \\
(14 \mathrm{M}) / \\
15(14 \mathrm{M})\end{array}$ & $\begin{array}{c}59.8 \pm 10.0 / \\
60.2 \pm 10.0\end{array}$ & ESS; $5.6 \pm 3.0 / 6,1 \pm 2.0$ & $26.7 \% / 20.0 \%$ & $9.5 / 4.6$ \\
\hline $\begin{array}{c}\text { Yong et al } \\
\text { [13] }\end{array}$ & 2011 & $\begin{array}{l}56(34 \mathrm{M}) / \\
68(38 \mathrm{M})\end{array}$ & $\begin{array}{c}65.4 \pm 9.1 / \\
59.3 \pm 9.1\end{array}$ & $\begin{array}{c}\text { EDS; } 66.1 \% / 2.9 \% \\
(E S S \geq 10) \\
\text { EDS; } 23.6 \% / 39.4 \% \\
\text { (Mean } S L<8 \text { min.) }\end{array}$ & $\begin{array}{c}49.1 \% / 65.1 \% \\
(\mathrm{AHI} \geq 5)\end{array}$ & $\begin{array}{c}12.5 \pm 15.6 / \\
12.2 \pm 13.1\end{array}$ \\
\hline
\end{tabular}

*Referred for sleepiness, ${ }^{* *}$ Controls were obtained from a population-based study, \#drug-naïve PD patients $\mathrm{SL}$, sleep latency; SRBD, sleep-related breathing disorders

Table 8. Polysomnographic studies evaluating sleep-related breathing disorders in PD 


\section{Conclusion}

Sleep disorders can occur in the early stages of PD and worsen as the disease progresses. The cause of sleep disorders in PD is multifactorial, reflecting PD-related pathology, various aspects of PD-related motor and non-motor symptoms, and comorbidity of primary sleep disorders. Early recognition of and active intervention for sleep disturbance is of great importance, as sleep disturbances significantly impair the quality of life of patients with PD.

\section{Author details}

Keisuke Suzuki ${ }^{1}$, Tomoyuki Miyamoto ${ }^{2}$, Masayuki Miyamoto ${ }^{1}$, Ayaka Numao ${ }^{1}$,

Hideki Sakuta ${ }^{1}$, Hiroaki Fujita ${ }^{1}$, Yuji Watanabe ${ }^{1}$, Masaoki Iwanami ${ }^{2}$ and Koichi Hirata ${ }^{1}$

1 Department of Neurology, Dokkyo Medical University, Japan

2 Department of Neurology, Dokkyo Medical University Koshigaya Hospital, Japan

\section{References}

[1] Jankovic J. Parkinson's disease: clinical features and diagnosis. J Neurol Neurosurg Psychiatry 2008;79(4):368-376.

[2] Chaudhuri KR, Schapira AH. Non-motor symptoms of Parkinson's disease: dopaminergic pathophysiology and treatment. Lancet Neurol 2009;8(5):464-474.

[3] Parkinson J. An essay on the shaking palsy. 1817. J Neuropsychiatry Clin Neurosci 2002;14(2):223-236; discussion 222.

[4] Lees AJ, Blackburn NA, Campbell VL. The nighttime problems of Parkinson's disease. Clin Neuropharmacol 1988;11(6):512-519.

[5] Suzuki K, Miyamoto M, Miyamoto T, Iwanami M, Hirata K. Sleep disturbances associated with Parkinson's disease. Parkinsons Dis 2011;2011:219056.

[6] Kumar S, Bhatia M, Behari M. Sleep disorders in Parkinson's disease. Mov Disord 2002;17(4):775-781.

[7] Tandberg E, Larsen JP, Karlsen K. A community-based study of sleep disorders in patients with Parkinson's disease. Mov Disord 1998;13(6):895-899.

[8] Diederich NJ, McIntyre DJ. Sleep disorders in Parkinson's disease: many causes, few therapeutic options. J Neurol Sci 2012;314(1-2):12-19. 
[9] Diederich NJ, Comella CL. Sleep disturbances in Parkinson's disease. In: Chokroverty S, Hening WA, Walters AS, editors. Sleep and Movement Disorders. Philadelphia: Elsevier Science; 2003. p. 478-488.

[10] Peeraully T, Yong MH, Chokroverty S, Tan EK. Sleep and Parkinson's disease: a review of case-control polysomnography studies. Mov Disord 2012;27(14):1729-1737.

[11] De Cock VC, Abouda M, Leu S, Oudiette D, Roze E, Vidailhet M, et al. Is obstructive sleep apnea a problem in Parkinson's disease? Sleep Med 2010;11(3):247-252.

[12] Happe S, Klosch G, Lorenzo J, Kunz D, Penzel T, Roschke J, et al. Perception of sleep: subjective versus objective sleep parameters in patients with Parkinson's disease in comparison with healthy elderly controls. Sleep perception in Parkinson's disease and controls. J Neurol 2005;252(8):936-943.

[13] Yong MH, Fook-Chong S, Pavanni R, Lim LL, Tan EK. Case control polysomnographic studies of sleep disorders in Parkinson's disease. PLoS One 2011;6(7):e22511.

[14] Arnulf I, Konofal E, Merino-Andreu M, Houeto JL, Mesnage V, Welter ML, et al. Parkinson's disease and sleepiness: an integral part of PD. Neurology 2002;58(7): 1019-1024.

[15] Brunner H, Wetter TC, Högl B, Yassouridis A, Trenkwalder C, Friess E. Microstructure of the non-rapid eye movement sleep electroencephalogram in patients with newly diagnosed Parkinson's disease: effects of dopaminergic treatment. Mov Disord 2002;17(5):928-933.

[16] Wetter TC, Brunner H, Högl B, Yassouridis A, Trenkwalder C, Friess E. Increased alpha activity in REM sleep in de novo patients with Parkinson's disease. Mov Disord 2001;16(5):928-933.

[17] Diederich NJ, Vaillant M, Leischen M, Mancuso G, Golinval S, Nati R, et al. Sleep apnea syndrome in Parkinson's disease. A case-control study in 49 patients. Mov Disord 2005;20(11):1413-1418.

[18] Wailke S, Herzog J, Witt K, Deuschl G, Volkmann J. Effect of controlled-release levodopa on the microstructure of sleep in Parkinson's disease. Eur J Neurol 2011;18(4): 590-596.

[19] Chaudhuri KR, Naidu Y. Early Parkinson's disease and non-motor issues. J Neurol 2008;255 Suppl 5:33-38.

[20] Shpirer I, Miniovitz A, Klein C, Goldstein R, Prokhorov T, Theitler J, et al. Excessive daytime sleepiness in patients with Parkinson's disease: a polysomnography study. Mov Disord 2006;21(9):1432-1438.

[21] Maria B, Sophia S, Michalis M, Charalampos L, Andreas P, John ME, et al. Sleep breathing disorders in patients with idiopathic Parkinson's disease. Respir Med 2003;97(10):1151-1157. 
[22] Buskova J, Klempir J, Majerova V, Picmausova J, Sonka K, Jech R, et al. Sleep disturbances in untreated Parkinson's disease. J Neurol 2011;258(12):2254-2259.

[23] Rye DB, Bliwise DL, Dihenia B, Gurecki P. FAST TRACK: daytime sleepiness in Parkinson's disease. J Sleep Res 2000;9(1):63-69.

[24] Chaudhuri KR, Pal S, DiMarco A, Whately-Smith C, Bridgman K, Mathew R, et al. The Parkinson's disease sleep scale: a new instrument for assessing sleep and nocturnal disability in Parkinson's disease. J Neurol Neurosurg Psychiatry 2002;73(6): 629-635.

[25] Högl B, Arnulf I, Comella C, Ferreira J, Iranzo A, Tilley B, et al. Scales to assess sleep impairment in Parkinson's disease: critique and recommendations. Mov Disord 2010;25(16):2704-2716.

[26] Abe K, Hikita T, Sakoda S. Sleep disturbances in Japanese patients with Parkinson's disease--comparing with patients in the UK. J Neurol Sci 2005;234(1-2):73-78.

[27] Margis R, Donis K, Schonwald SV, Fagondes SC, Monte T, Martin-Martinez P, et al. Psychometric properties of the Parkinson's Disease Sleep Scale--Brazilian version. Parkinsonism Relat Disord 2009;15(7):495-499.

[28] Martinez-Martin P, Salvador C, Menendez-Guisasola L, Gonzalez S, Tobias A, Almazan J, et al. Parkinson's Disease Sleep Scale: validation study of a Spanish version. Mov Disord 2004;19(10):1226-1232.

[29] Suzuki K, Okuma Y, Hattori N, Kamei S, Yoshii F, Utsumi H, et al. Characteristics of sleep disturbances in Japanese patients with Parkinson's disease. A study using Parkinson's disease sleep scale. Mov Disord 2007;22(9):1245-1251.

[30] Wang G, Cheng Q, Zeng J, Bai L, Liu GD, Zhang Y, et al. Sleep disorders in Chinese patients with Parkinson's disease: validation study of a Chinese version of Parkinson's disease sleep scale. J Neurol Sci 2008;271(1-2):153-157.

[31] Suzuki K, Miyamoto M, Miyamoto T, Okuma Y, Hattori N, Kamei S, et al. Correlation between depressive symptoms and nocturnal disturbances in Japanese patients with Parkinson's disease. Parkinsonism Relat Disord 2009;15(1):15-19.

[32] Dhawan V, Dhoat S, Williams AJ, Dimarco A, Pal S, Forbes A, et al. The range and nature of sleep dysfunction in untreated Parkinson's disease (PD). A comparative controlled clinical study using the Parkinson's disease sleep scale and selective polysomnography. J Neurol Sci 2006;248(1-2):158-162.

[33] Trenkwalder C, Kohnen R, Högl B, Metta V, Sixel-Döring F, Frauscher B, et al. Parkinson's disease sleep scale-validation of the revised version PDSS-2. Mov Disord 2011;26(4):644-652. 
[34] Suzuki K, Miyamoto M, Miyamoto T, Tatsumoto M, Watanabe Y, Suzuki S, et al. Nocturnal disturbances and restlessness in Parkinson's disease: using the Japanese version of the Parkinson's disease sleep scale-2. J Neurol Sci 2012;318(1-2):76-81.

[35] Trenkwalder C, Kies B, Rudzinska M, Fine J, Nikl J, Honczarenko K, et al. Rotigotine effects on early morning motor function and sleep in Parkinson's disease: a doubleblind, randomized, placebo-controlled study (RECOVER). Mov Disord 2011;26(1): 90-99.

[36] van Hilten B, Hoff JI, Middelkoop HA, van der Velde EA, Kerkhof GA, Wauquier A, et al. Sleep disruption in Parkinson's disease. Assessment by continuous activity monitoring. Arch Neurol 1994;51(9):922-928.

[37] Factor SA, McAlarney T, Sanchez-Ramos JR, Weiner WJ. Sleep disorders and sleep effect in Parkinson's disease. Mov Disord 1990;5(4):280-285.

[38] Chaudhuri KR, Martinez-Martin P. Clinical assessment of nocturnal disability in Parkinson's disease: the Parkinson's Disease Sleep Scale. Neurology 2004;63(8 Suppl 3):S17-20.

[39] Chaudhuri KR, Prieto-Jurcynska C, Naidu Y, Mitra T, Frades-Payo B, Tluk S, et al. The nondeclaration of nonmotor symptoms of Parkinson's disease to health care professionals: an international study using the nonmotor symptoms questionnaire. Mov Disord 2010;25(6):704-709.

[40] Winge K, Fowler CJ. Bladder dysfunction in Parkinsonism: mechanisms, prevalence, symptoms, and management. Mov Disord 2006;21(6):737-745.

[41] Kuno S, Mizuta E, Yamasaki S, Araki I. Effects of pergolide on nocturia in Parkinson's disease: three female cases selected from over 400 patients. Parkinsonism Relat Disord 2004;10(3):181-187.

[42] Seif C, Herzog J, van der Horst C, Schrader B, Volkmann J, Deuschl G, et al. Effect of subthalamic deep brain stimulation on the function of the urinary bladder. Ann Neurol 2004;55(1):118-120.

[43] Barone P, Antonini A, Colosimo C, Marconi R, Morgante L, Avarello TP, et al. The PRIAMO study: A multicenter assessment of nonmotor symptoms and their impact on quality of life in Parkinson's disease. Mov Disord 2009;24(11):1641-1649.

[44] Starkstein SE, Preziosi TJ, Robinson RG. Sleep disorders, pain, and depression in Parkinson's disease. Eur Neurol 1991;31(6):352-355.

[45] Goetz CG, Wilson RS, Tanner CM, Garron DC. Relationships among pain, depression, and sleep alterations in Parkinson's disease. Adv Neurol 1987;45:345-347.

[46] Ford B. Pain in Parkinson's disease. Mov Disord 2010;25 Suppl 1:S98-103. 
[47] Reuter I, Ellis CM, Chaudhuri KR. Nocturnal subcutaneous apomorphine infusion in Parkinson's disease and restless legs syndrome. Acta Neurol Scand 1999;100(3): 163-167.

[48] Arnulf I, Bejjani BP, Garma L, Bonnet AM, Houeto JL, Damier P, et al. Improvement of sleep architecture in PD with subthalamic nucleus stimulation. Neurology 2000;55(11):1732-1734.

[49] Chaudhuri KR, Martinez-Martin P, Rolfe KA, Cooper J, Rockett CB, Giorgi L, et al. Improvements in nocturnal symptoms with ropinirole prolonged release in patients with advanced Parkinson's disease. Eur J Neurol 2012;19(1):105-113.

[50] Comella CL, Morrissey M, Janko K. Nocturnal activity with nighttime pergolide in Parkinson disease: a controlled study using actigraphy. Neurology 2005;64(8): 1450-1451.

[51] Goetz CG. Hallucinations in Parkinson's disease: the clinical syndrome. Adv Neurol 1999;80:419-423.

[52] Goetz CG. New developments in depression, anxiety, compulsiveness, and hallucinations in Parkinson's disease. Mov Disord 2010;25 Suppl 1:S104-109.

[53] Nausieda PA, Weiner WJ, Kaplan LR, Weber S, Klawans HL. Sleep disruption in the course of chronic levodopa therapy: an early feature of the levodopa psychosis. Clin Neuropharmacol 1982;5(2):183-194.

[54] Reijnders JS, Ehrt U, Weber WE, Aarsland D, Leentjens AF. A systematic review of prevalence studies of depression in Parkinson's disease. Mov Disord 2008;23(2): 183-189; quiz 313.

[55] Borek LL, Kohn R, Friedman JH. Mood and sleep in Parkinson's disease. J Clin Psychiatry 2006;67(6):958-963.

[56] Happe S, Schrödl B, Faltl M, Müller C, Auff E, Zeitlhofer J. Sleep disorders and depression in patients with Parkinson's disease. Acta Neurol Scand 2001;104(5):275-280.

[57] Aarsland D, Pahlhagen S, Ballard CG, Ehrt U, Svenningsson P. Depression in Parkinson disease--epidemiology, mechanisms and management. Nat Rev Neurol 2012;8(1): $35-47$.

[58] Cummings JL. Depression and Parkinson's disease: a review. Am J Psychiatry 1992;149(4):443-454.

[59] Barone P, Poewe W, Albrecht S, Debieuvre C, Massey D, Rascol O, et al. Pramipexole for the treatment of depressive symptoms in patients with Parkinson's disease: a randomised, double-blind, placebo-controlled trial. Lancet Neurol 2010;9(6):573-580.

[60] Mahowald M, Schenck C. REM sleep parasomnias. In: Kryger M, Roth T, Dement W, editors. Principles and Practice of Sleep Medicine. 5th ed. Philadelphia: Saunders; 2010. p. 1083-1097. 
[61] Ondo WG, Dat Vuong K, Khan H, Atassi F, Kwak C, Jankovic J. Daytime sleepiness and other sleep disorders in Parkinson's disease. Neurology 2001;57(8):1392-1396.

[62] Suzuki K, Miyamoto T, Miyamoto M, Okuma Y, Hattori N, Kamei S, et al. Excessive daytime sleepiness and sleep episodes in Japanese patients with Parkinson's disease. J Neurol Sci 2008;271(1-2):47-52.

[63] Tandberg E, Larsen JP, Karlsen K. Excessive daytime sleepiness and sleep benefit in Parkinson's disease: a community-based study. Mov Disord 1999;14(6):922-927.

[64] Tan EK, Lum SY, Fook-Chong SM, Teoh ML, Yih Y, Tan L, et al. Evaluation of somnolence in Parkinson's disease: comparison with age- and sex-matched controls. Neurology 2002;58(3):465-468.

[65] Arnulf I, Leu S, Oudiette D. Abnormal sleep and sleepiness in Parkinson's disease. Curr Opin Neurol 2008;21(4):472-477.

[66] Overeem S, Scammell TE, Lammers GJ. Hypocretin/orexin and sleep: implications for the pathophysiology and diagnosis of narcolepsy. Curr Opin Neurol 2002;15(6): 739-745.

[67] Yasui K, Inoue Y, Kanbayashi T, Nomura T, Kusumi M, Nakashima K. CSF orexin levels of Parkinson's disease, dementia with Lewy bodies, progressive supranuclear palsy and corticobasal degeneration. J Neurol Sci 2006;250(1-2):120-123.

[68] Compta Y, Santamaria J, Ratti L, Tolosa E, Iranzo A, Munoz E, et al. Cerebrospinal hypocretin, daytime sleepiness and sleep architecture in Parkinson's disease dementia. Brain 2009;132(Pt 12):3308-3317.

[69] Fronczek R, Overeem S, Lee SY, Hegeman IM, van Pelt J, van Duinen SG, et al. Hypocretin (orexin) loss in Parkinson's disease. Brain 2007;130(Pt 6):1577-1585.

[70] Thannickal TC, Lai YY, Siegel JM. Hypocretin (orexin) cell loss in Parkinson's disease. Brain 2007;130(Pt 6):1586-1595.

[71] Brodsky MA, Godbold J, Roth T, Olanow CW. Sleepiness in Parkinson's disease: a controlled study. Mov Disord 2003;18(6):668-672.

[72] Paus S, Brecht HM, Koster J, Seeger G, Klockgether T, Wullner U. Sleep attacks, daytime sleepiness, and dopamine agonists in Parkinson's disease. Mov Disord 2003;18(6):659-667.

[73] Hobson DE, Lang AE, Martin WR, Razmy A, Rivest J, Fleming J. Excessive daytime sleepiness and sudden-onset sleep in Parkinson disease: a survey by the Canadian Movement Disorders Group. JAMA 2002;287(4):455-463.

[74] Kaynak D, Kiziltan G, Kaynak H, Benbir G, Uysal O. Sleep and sleepiness in patients with Parkinson's disease before and after dopaminergic treatment. Eur J Neurol 2005;12(3):199-207. 
[75] Abbott RD, Ross GW, White LR, Tanner CM, Masaki KH, Nelson JS, et al. Excessive daytime sleepiness and subsequent development of Parkinson disease. Neurology 2005;65(9):1442-1446.

[76] Gjerstad MD, Alves G, Wentzel-Larsen T, Aarsland D, Larsen JP. Excessive daytime sleepiness in Parkinson disease: is it the drugs or the disease? Neurology 2006;67(5): 853-858.

[77] Monti JM, Monti D. The involvement of dopamine in the modulation of sleep and waking. Sleep Med Rev 2007;11(2):113-133.

[78] Bliwise DL, Trotti LM, Wilson AG, Greer SA, Wood-Siverio C, Juncos JJ, et al. Daytime alertness in Parkinson's disease: potentially dose-dependent, divergent effects by drug class. Mov Disord 2012;27(9):1118-1124.

[79] Trenkwalder C, Arnulf I. Principles and Practice of Sleep Medicine. In: Kryger MH, Roth T, Dement WC, editors. Parkinsonism. 5th ed. St. Louis: Saunders; 2010. p. 980-992.

[80] De Cock VC, Vidailhet M, Arnulf I. Sleep disturbances in patients with parkinsonism. Nat Clin Pract Neurol 2008;4(5):254-266.

[81] Schenck CH, Bundlie SR, Ettinger MG, Mahowald MW. Chronic behavioral disorders of human REM sleep: a new category of parasomnia. Sleep 1986;9(2):293-308.

[82] Postuma RB, Gagnon JF, Montplaisir JY. REM Sleep Behavior Disorder and Prodromal Neurodegeneration - Where Are We Headed? Tremor Other Hyperkinet Mov (N Y) 2013;3.

[83] Schenck CH, Bundlie SR, Mahowald MW. Delayed emergence of a parkinsonian disorder in $38 \%$ of 29 older men initially diagnosed with idiopathic rapid eye movement sleep behaviour disorder. Neurology 1996;46(2):388-393.

[84] Postuma RB, Gagnon JF, Vendette M, Fantini ML, Massicotte-Marquez J, Montplaisir J. Quantifying the risk of neurodegenerative disease in idiopathic REM sleep behavior disorder. Neurology 2009;72(15):1296-1300.

[85] Boeve BF, Silber MH, Ferman TJ, Lin SC, Benarroch EE, Schmeichel AM, et al. Clinicopathologic correlations in 172 cases of rapid eye movement sleep behavior disorder with or without a coexisting neurologic disorder. Sleep Med 2013;14(8):754-762.

[86] Gagnon JF, Vendette M, Postuma RB, Desjardins C, Massicotte-Marquez J, Panisset $\mathrm{M}$, et al. Mild cognitive impairment in rapid eye movement sleep behavior disorder and Parkinson's disease. Ann Neurol 2009;66(1):39-47.

[87] Miyamoto T, Miyamoto M, Inoue Y, Usui Y, Suzuki K, Hirata K. Reduced cardiac 123I-MIBG scintigraphy in idiopathic REM sleep behavior disorder. Neurology 2006;67(12):2236-2238.

[88] Miyamoto T, Miyamoto M, Iwanami M, Hirata K. Olfactory dysfunction in Japanese patients with idiopathic REM sleep behavior disorder: comparison of data using the 
university of Pennsylvania smell identification test and odor stick identification test for Japanese. Mov Disord 2010;25(10):1524-1526.

[89] Postuma RB, Gagnon JF, Vendette M, Montplaisir JY. Markers of neurodegeneration in idiopathic rapid eye movement sleep behaviour disorder and Parkinson's disease. Brain 2009;132(Pt 12):3298-3307.

[90] Iwanami M, Miyamoto T, Miyamoto M, Hirata K, Takada E. Relevance of substantia nigra hyperechogenicity and reduced odor identification in idiopathic REM sleep behavior disorder. Sleep Med 2010;11(4):361-365.

[91] Postuma RB, Gagnon JF, Rompre S, Montplaisir JY. Severity of REM atonia loss in idiopathic REM sleep behavior disorder predicts Parkinson disease. Neurology 2010;74(3):239-244.

[92] Miyamoto M, Miyamoto T. Neuroimaging of rapid eye movement sleep behavior disorder: transcranial ultrasound, single-photon emission computed tomography, and positron emission tomography scan data. Sleep Med 2013;14(8):739-743.

[93] Boissard R, Fort P, Gervasoni D, Barbagli B, Luppi PH. Localization of the GABAergic and non-GABAergic neurons projecting to the sublaterodorsal nucleus and potentially gating paradoxical sleep onset. Eur J Neurosci 2003;18(6):1627-1639.

[94] Sastre JP, Jouvet M. [Oneiric behavior in cats]. Physiol Behav 1979;22(5):979-989.

[95] Boeve BF. REM sleep behavior disorder: Updated review of the core features, the REM sleep behavior disorder-neurodegenerative disease association, evolving concepts, controversies, and future directions. Ann N Y Acad Sci 2010;1184:15-54.

[96] Garcia-Lorenzo D, Longo-Dos Santos C, Ewenczyk C, Leu-Semenescu S, Gallea C, Quattrocchi G, et al. The coeruleus/subcoeruleus complex in rapid eye movement sleep behaviour disorders in Parkinson's disease. Brain 2013;136(Pt 7):2120-2129.

[97] Postuma RB, Gagnon JF, Vendette M, Charland K, Montplaisir J. Manifestations of Parkinson disease differ in association with REM sleep behavior disorder. Mov Disord 2008;23(12):1665-1672.

[98] Postuma RB, Gagnon JF, Vendette M, Charland K, Montplaisir J. REM sleep behaviour disorder in Parkinson's disease is associated with specific motor features. J Neurol Neurosurg Psychiatry 2008;79(10):1117-1121.

[99] Miyamoto T, Miyamoto M, Iwanami M, Hirata K. Cardiac 123I-MIBG accumulation in Parkinson's disease differs in association with REM sleep behavior disorder. Parkinsonism Relat Disord 2011;17(3):219-220.

[100] Nomura T, Inoue Y, Hogl B, Uemura Y, Kitayama M, Abe T, et al. Relationship between (123)I-MIBG scintigrams and REM sleep behavior disorder in Parkinson's disease. Parkinsonism Relat Disord 2010;16(10):683-685. 
[101] Postuma RB, Bertrand JA, Montplaisir J, Desjardins C, Vendette M, Rios Romenets S, et al. Rapid eye movement sleep behavior disorder and risk of dementia in Parkinson's disease: a prospective study. Mov Disord 2012;27(6):720-726.

[102] Nomura T, Inoue Y, Kagimura T, Nakashima K. Clinical significance of REM sleep behavior disorder in Parkinson's disease. Sleep Med 2013;14(2):131-135.

[103] Sixel-Döring F, Trautmann E, Mollenhauer B, Trenkwalder C. Associated factors for REM sleep behavior disorder in Parkinson disease. Neurology 2011;77(11):1048-1054.

[104] Bugalho P, da Silva JA, Neto B. Clinical features associated with REM sleep behavior disorder symptoms in the early stages of Parkinson's disease. J Neurol 2011;258(1): 50-55.

[105] Alves G, Larsen JP, Emre M, Wentzel-Larsen T, Aarsland D. Changes in motor subtype and risk for incident dementia in Parkinson's disease. Mov Disord 2006;21(8): 1123-1130.

[106] Miyamoto T, Miyamoto M, Iwanami M, Kobayashi M, Nakamura M, Inoue $\mathrm{Y}$, et al. The REM sleep behavior disorder screening questionnaire: validation study of a Japanese version. Sleep Med 2009;10(10):1151-1154.

[107] Suzuki K, Miyamoto T, Miyamoto M, Watanabe Y, Suzuki S, Tatsumoto M, et al. Probable rapid eye movement sleep behavior disorder, nocturnal disturbances and quality of life in patients with Parkinson's disease: a case-controlled study using the rapid eye movement sleep behavior disorder screening questionnaire. BMC Neurol 2013;13:18.

[108] Plomhause L, Dujardin K, Duhamel A, Delliaux M, Derambure P, Defebvre L, et al. Rapid eye movement sleep behavior disorder in treatment-naive Parkinson disease patients. Sleep Med 2013.

[109] De Cock VC, Vidailhet M, Leu S, Texeira A, Apartis E, Elbaz A, et al. Restoration of normal motor control in Parkinson's disease during REM sleep. Brain 2007;130(Pt 2): 450-456.

[110] Schenck CH, Mahowald MW, Kim SW, O'Connor KA, Hurwitz TD. Prominent eye movements during NREM sleep and REM sleep behavior disorder associated with fluoxetine treatment of depression and obsessive-compulsive disorder. Sleep 1992;15(3):226-235.

[111] Boeve BF, Silber MH, Ferman TJ. Melatonin for treatment of REM sleep behavior disorder in neurologic disorders: results in 14 patients. Sleep Med 2003;4(4):281-284.

[112] Kunz D, Bes F. Melatonin effects in a patient with severe REM sleep behavior disorder: case report and theoretical considerations. Neuropsychobiology 1997;36(4): 211-214. 
[113] Shinno H, Kamei M, Nakamura Y, Inami Y, Horiguchi J. Successful treatment with Yi-Gan San for rapid eye movement sleep behavior disorder. Prog Neuropsychopharmacol Biol Psychiatry 2008;32(7):1749-1751.

[114] Clemens S, Rye D, Hochman S. Restless legs syndrome: revisiting the dopamine hypothesis from the spinal cord perspective. Neurology 2006;67(1):125-130.

[115] Bara-Jimenez W, Aksu M, Graham B, Sato S, Hallett M. Periodic limb movements in sleep: state-dependent excitability of the spinal flexor reflex. Neurology 2000;54(8): 1609-1616.

[116] Tergau F, Wischer S, Paulus W. Motor system excitability in patients with restless legs syndrome. Neurology 1999;52(5):1060-1063.

[117] Tyvaert L, Houdayer E, Devanne H, Bourriez JL, Derambure P, Monaca C. Cortical involvement in the sensory and motor symptoms of primary restless legs syndrome. Sleep Med 2009;10(10):1090-1096.

[118] Iranzo A, Comella CL, Santamaria J, Oertel W. Restless legs syndrome in Parkinson's disease and other neurodegenerative diseases of the central nervous system. Mov Disord 2007;22 Suppl 18:S424-430.

[119] Möller JC, Unger M, Stiasny-Kolster K, Oertel WH. Restless Legs Syndrome (RLS) and Parkinson's disease (PD)-related disorders or different entities? J Neurol Sci 2010;289(1-2):135-137.

[120] Earley CJ, Kuwabara H, Wong DF, Gamaldo C, Salas R, Brasic J, et al. The dopamine transporter is decreased in the striatum of subjects with restless legs syndrome. Sleep 2011;34(3):341-347.

[121] Trenkwalder C, Walters AS, Hening WA, Chokroverty S, Antonini A, Dhawan V, et al. Positron emission tomographic studies in restless legs syndrome. Mov Disord 1999;14(1):141-145.

[122] Connor JR, Wang XS, Allen RP, Beard JL, Wiesinger JA, Felt BT, et al. Altered dopaminergic profile in the putamen and substantia nigra in restless leg syndrome. Brain 2009;132(Pt 9):2403-2412.

[123] Earley CJ, Connor JR, Beard JL, Malecki EA, Epstein DK, Allen RP. Abnormalities in CSF concentrations of ferritin and transferrin in restless legs syndrome. Neurology 2000;54(8):1698-1700.

[124] Mizuno S, Mihara T, Miyaoka T, Inagaki T, Horiguchi J. CSF iron, ferritin and transferrin levels in restless legs syndrome. J Sleep Res 2005;14(1):43-47.

[125] Allen RP, Barker PB, Wehrl F, Song HK, Earley CJ. MRI measurement of brain iron in patients with restless legs syndrome. Neurology 2001;56(2):263-265. 
[126] Schmidauer C, Sojer M, Seppi K, Stockner H, Hogl B, Biedermann B, et al. Transcranial ultrasound shows nigral hypoechogenicity in restless legs syndrome. Ann Neurol 2005;58(4):630-634.

[127] Kwon DY, Seo WK, Yoon HK, Park MH, Koh SB, Park KW. Transcranial brain sonography in Parkinson's disease with restless legs syndrome. Mov Disord 2010;25(10): 1373-1378.

[128] Gjerstad MD, Tysnes OB, Larsen JP. Increased risk of leg motor restlessness but not RLS in early Parkinson disease. Neurology 2011;77(22):1941-1946.

[129] Poewe W, Högl B. Akathisia, restless legs and periodic limb movements in sleep in Parkinson's disease. Neurology 2004;63(8 Suppl 3):S12-16.

[130] Chaudhuri KR, Healy DG, Schapira AH, National Institute for Clinical E. Non-motor symptoms of Parkinson's disease: diagnosis and management. Lancet Neurol 2006;5(3):235-245.

[131] Ondo WG, Vuong KD, Jankovic J. Exploring the relationship between Parkinson disease and restless legs syndrome. Arch Neurol 2002;59(3):421-424.

[132] Lee JE, Shin HW, Kim KS, Sohn YH. Factors contributing to the development of restless legs syndrome in patients with Parkinson disease. Mov Disord 2009;24(4): 579-582.

[133] Shimohata T, Nishizawa M. Sleep disturbance in patients with Parkinson's disease presenting with leg motor restlessness. Parkinsonism Relat Disord 2013;19(5): 571-572.

[134] Trotti LM, Bliwise DL. No increased risk of obstructive sleep apnea in Parkinson's disease. Mov Disord 2010;25(13):2246-2249.

[135] Suzuki K, Miyamoto M, Miyamoto T, Suzuki S, Watanabe Y, Numao A, et al. Snoring is associated with an impaired motor function, disease severity and the quality of life but not with excessive daytime sleepiness in patients with Parkinson's disease. Intern Med 2013;52(8):863-869. 
